\title{
A DECISION SUPPORT FRAMEWORK FOR THE RISK ASSESSMENT OF COASTAL EROSION IN THE YANGTZE DELTA
}

\author{
Li Xing ${ }^{a, *}$, Zhou Yunxuan $^{a}$, Shen Fang $^{a}$, Kuang Runyuan $^{a}$, Wu Wen $^{a}$, Zheng Zongsheng $^{b}$ \\ ${ }^{a}$ State Key Laboratory of Estuarine and Coastal Research, East China Normal University, 3663 Zhongshan North Road, Shanghai 200062 - \\ li_xing99@yahoo.com.cn, (zhouyx, fshen)@sklec.ecnu.edu.cn, rykuang@163.com,wen1722003@tom.com \\ ${ }^{b}$ College of Information, Shanghai Ocean University, 999 Huchenghuan Road, Shanghai 201306, China - zszheng@ shou.edu.cn
}

KEY WORDS: Coastal erosion, Risk assessment, GIS, Decision support framework, the Yangtze Delta

\begin{abstract}
:
Coastal erosion is an issue of widespread concern. As one of the most important economic regions in China, the coast of the Yangtze Delta has been showing a trend towards erosion with global warming and the increasing human activities in the catchment and its estuary. Currently, most published studies about coastal erosion in the area focused on the causes and types of erosion. This paper presents a Decision Support Framework (DSF) for the risk assessment of coastal erosion in consideration of the potential management problems and challenges for economic development in the coastal zone of the Yangtze Delta. The framework consists of four major components: integrated database, GIS-based risk assessment models, scenarios generator and visualization toolkit. Especially, we developed a GIS-based risk assessment model for the muddy coasts of Yangtze Delta. An Analytic Hierarchy Process (AHP) method, which is instrumental in combining computer intelligence and experts' knowledge, was used to weight the variables of the model. The assessment results show the validity of the approach. Accordingly, the DSF will make the specialized data and information more accessible to managers, and has an extensive capability to facilitate communication and synergetic work between humans and computers. In this way, it is expected to make manager make more scientific decision.
\end{abstract}

\section{INTRODUCTION}

Coastal erosion is an issue of widespread concern. It is estimated that at least $70 \%$ of the sandy beaches in the world is retreating at a rate of 0.5-1.0 m/year (Bird, 1985). Moreover, intensified human activities and accelerated sea level rise will aggravate the coastal erosion in the future century (Zhang et al., 2004). The coasts, especially of the deltas and megadeltas, which are recognized as highly susceptible to human and natural impacts, will be exposed to increasing risks (Nicholls et al., 2007). In China, coastal erosion is also ubiquitous in most coastal area (Sheng and Zhu, 2002; Xia et al., 1993). Zuo et al. (2009) reported that most of the coasts between the mouth of the Luan River and the city of Qinhuangdao (northeast Bohai Sea, China) have been suffering from extensive erosion with an average rate of $3.7 \mathrm{~m} /$ year during 1986-2000. The abandoned Huanghe delta has been subjected to dramatic erosion since 1855 when the Huanghe River shifted its channel (Zhang et al., 1998). As far as the Yangtze Delta is concerned, the huge amount of sediment load from the Yangtze River contributed to the successive accretion of the Delta in the past. However, contemporarily global warming and the construction of large hydraulic engineering works in the catchment and its estuary significantly decelerate the trend, and the delta degradation has been observed since 2003 (Yang et al., 2007). Considering the combined influence of the planning dams and the South-to-North Water Diversion Project, the anticipated coastal erosion problem will be even worse.

Since the Yangtze Delta is one of the most important economic regions in China, a long-term coastal spatial planning will be an inevitable issue for the local governments. While, most coasts in the Yangtze Delta are typically muddy that are characterized by extremely complex land-sea interaction. In view of the complexity and uncertainty of human and natural dimension under the circumstances of global change, the need for integrating human and computer intelligence necessitates a Decision Support Framework (DSF) for the risk assessment of coastal erosion. Although decision support has been involved in Integrated Coastal

\footnotetext{
${ }^{*}$ Corresponding author.
}

Zone Management (ICZM) early in 1990s, it has a very limited application in coastal management (Van Kouwen et al., 2008). And most of the existing decision support related to coastal erosion was potentially underlain by the complete physical, socioeconomic datasets and the deterministic solutions. In fact, in many developing countries it is usually possible that some key parameters affecting model output are unavailable (Szlafsztein and Sterr, 2007), and the relevant research is still inadequate. In the case of Yangtze Delta, most current published studies about coastal erosion were focused on the causes and types of erosion (Cai et al., 2009; Chen et al., 1988; Gao and Wang, 2008; Hori et al., 2002; Milliman et al., 1985; Yang et al., 2001, 2006). This paper presents a decision support framework (DSF) for the risk assessment of coastal erosion in consideration of the potential management problems and challenges for economic development in the coastal zone of the Yangtze Delta.

Our primary goal is to develop a framework to provide the theoretical and methodological basis for the future practical application, further to bridge the gap between scientists and managers to provide the intelligence basis for the scientific coastal management.

\section{WHY NOT DECISION SUPPORT SYSTEM (DSS)?}

The idea of DSS originated in the mid-1960s (Power, 2008), and has been applied extensively in many fields. In comparison, its application for coastal management is very limited (Wiggins, 2004). The causes have been discussed by several literatures ( $c f$. Jones et al., 2002; Uran and Janssen, 2003; Van Kouwen et al., 2008; Westmacott, 2001). We avoid the term DSS because of several reasons as follows:

- Nowadays, the development of computer technology has made that few computer systems of any significance haven't some functions of supporting decision making in some forms to some extent (Alter, 2004). So DSS maybe a still popular but obvious antiquated label. 
- The technological and administrative background is still lack for the Yangtze Delta to develop DSS for coastal management (Lau, 2005; Shi et al., 2001). China is a developing country, and the Yangtze Delta is one of its economic centers. The local authorities mainly draw their attention on the economic development. Scientific coastal management implies to give up some economic considerations to some extent. And the specific technological conditions need to be improved further.

- Coastal erosion is a complex natural phenomenon, especially to muddy coast. Although the information technology is quite advanced, decisions still have to mainly depend on experienced specialists and managers. In the first instance, we need to improve the computer system by incorporating more sophisticated models. On the other hand, it is a gradual process for human beings to understand nature. Although a great number of researches have been conducted in the Yangtze Delta over the past decades, our knowledge is very limited as to the complexity of coastal erosion. So a tool or platform is needed to facilitate the understanding the natural and human-induced coastal behaviors. DSS, as a technical artifact, can't explicitly express these meanings.

Instead, we use "decision support framework" which has three characteristics: (1) to provide reference data to promote the effectiveness of decision making; (2) to provide analysis models to promote the efficiency of decision making; (3) to bridge the gap between scientists and policy-makers by providing the scenario and visualization tools, and eventually facilitate "coevolution" of human and computer.

\section{DECISION SUPPORT FRAMEWORK CHALLENGES IN THE YANGTZE DELTA}

The Yangtze Delta is formed mainly by riverine sediments from the Yangtze River that depends on the river discharge and ocean processes (Chen et al., 1959) (Figure 1). The coasts are mostly muddy, along which the muddy tidal flat are extensively distributed with varying width. The coastal development is influenced by many factors, including the history of coastal evolution, ocean dynamic, terrigenous materials, human activities, socio-economic conditions, etc., so the coastal environment is very complex.

The Yangtze Delta is a tide-dominated coastal environment (Saito et al., 2001). The mean annual water discharge of the Yangtze River is $9.24 \times 10^{11} \mathrm{~m}^{3}$ that transports $4.80 \times 10^{8}$ tons of sediment to the sea (Yang et al., 2006). The water discharge has an evident yearly and seasonal variation (Chen et al., 2001). The annual tidal prism into the Yangtze estuary has a total volume of $8.40 \times 10^{12} \mathrm{~m}^{3}$, which is an order of magnitude higher than the water discharge (Chen et al., 1988). Along the coasts, the semidiurnal tide is predominant with different tidal ranges. The average tidal range is $1.5-1.7 \mathrm{~m}$ around the abandoned Yellow River mouth and along the southern part of the North Jiangsu coast (Zhou et al., 1994). And the mean tidal range is $2.7 \mathrm{~m}$ near the Yangtze River mouth, and the maximum tidal range approaches $4.6 \mathrm{~m}$ (Shen et al., 1988).

The Yangtze Delta is one of the most important industrial and agricultural areas in China where economic development is the first priority of local governments. With $2 \%$ of the area and about $10 \%$ of the population of China, the region contributed to $26 \%$ of national GDP in the first half of 2008 (http://www.ocn. com. $\mathrm{cn} /$ reports/2006079changsanjiao.htm, in Chinese). Along with the progress of urbanization and industrialization, more tidal flats will be reclaimed in Yangtze Delta; as a result, vulnerable coast environments will be further disturbed. Meanwhile, the delta is one of the most serious subsidence areas in China (Han et al., 2008). During 2001-2006, the mean subsidence rate is 12.7 $\mathrm{mm} /$ year in Shanghai (Gong, 2008). Moreover, the fluvial sediment to the coastal ocean will continually reduce as the large hydraulic engineering works are brought on line in its catchment. Additionally, the sea level is rising at a significant rate under the influence of global warming (Shi et al., 2001). It is estimated that the relative sea level rise from 1990 to 2050 will be $50 \mathrm{~cm}$ in Shanghai Municipality, $20-30 \mathrm{~cm}$ in the coastal plain of North Jiangsu and the northern bank of Hangzhou Bay, and the 100year storm surge level will increase by $38-44 \mathrm{~cm}$ when the sea level reaches $50 \mathrm{~cm}$ (Shi et al., 2000). These will undoubtedly increase the risk of coastal erosion in Yangtze Delta.

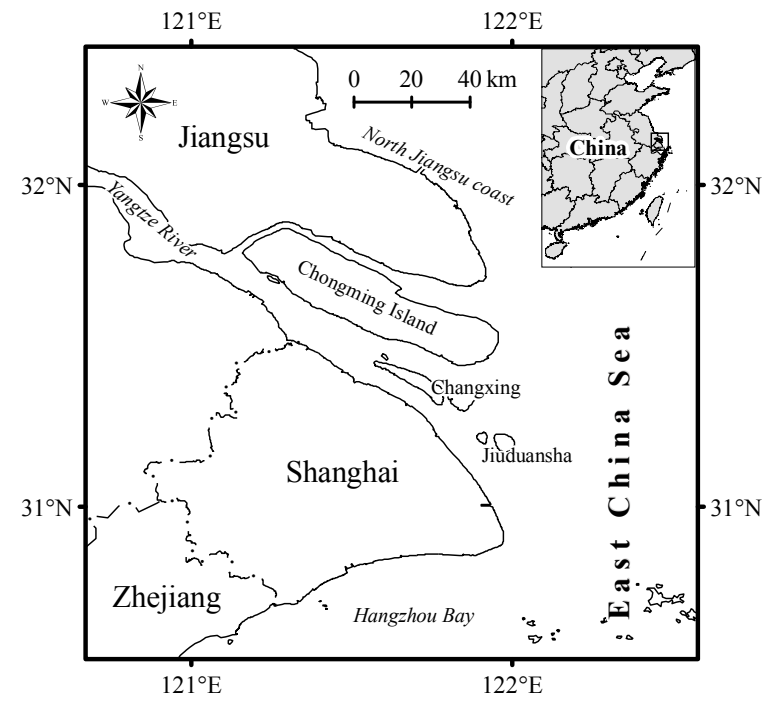

Figure 1: Location of the Yangtze Delta

\section{THE DECISION SUPPORT FRAMEWORK}

The DSF consists of four major components: integrated database, GIS-based risk assessment models, scenarios generator and visualization toolkit. At first, it is necessary for us to provide definitions of three concepts in order to the further description of the DSF and discussion.

a) Visualization: a set of computer-generated static or animated, 2D or 3D character, graphics and image to depict the properties and process of physical objects in some certain aspects, with the intention of visually communicating some information to specified audiences.

b) Scenario: an expression of a subset of the complete parameters that can completely depict a complex system. Scenarios are neither predictions nor forecasts, but rather attempt to picture the situation under specified conditions, by this way, to intuitively grasp the essence of events or phenomena.

c) Decision support framework: a conceptual structure comprising personnel and computer programs, in which manager or decision-maker and computer programs interact to make decisions and "coevolve".

The three concepts are defined mainly based on the consideration of highly complex, dynamic environment, where scientists fail to 
provide managers or decision-makers with effective information what they need most (Tribbia and Moser, 2008). Therefore, visualization and scenario act as tools to help those without technical expertise understand the complex physical objects and update their own knowledge. The framework contributes to combine the strengths of both human intelligence and computer program, and promote the evolution of either, and by which the framework will improve with time. In following subsections we will discuss in detail four components of DSF.

The integrated database provides a means of storage, management and retrieval all relevant data, which support the risk assessment of coastal erosion in the Yangtze Delta. It contains direct indicators data (can be directly input to model as a parameter), input data (for calculations of direct indicators) and auxiliary data (to aid visualization and scenario). These data are represented respectively in raster and vector format, and the involved data types mainly have, administrative boundary, remote sensing image, geomorphology and geology, elevation, bathymetry, shoreline, sediment transport, riverine discharge, tidal regime, wave climate, sea level rise, subsidence, extreme historical events, Land Cover/Land Use (LCLU), infrastructure, ecological hotspot, population density, etc.

GIS-based Risk Assessment Model is the core component of the DSF. It mainly is used to quantify the risk level of coastal erosion for the muddy coasts of the Yangtze Delta, and further serve as a general framework for the case of muddy coasts where possible. It will work mainly by the following steps: (i) to define homogeneous units; (ii) to identify the vulnerability indicators and to evaluate vulnerability; (iii) to identify the impact indicators and to evaluate hazard; (iv) to evaluate risk. All the calculations will be done in GIS environment where ones are allowed to take advantage of its enhanced spatial analysis capabilities.

The scenario generator is used to generate the impact of coastal erosion under varying conditions which maybe existent, hypothetic, simulated or predicted. In chief, it assists users to understand the coastal environment, define the vulnerability and impact indicators, and determine weights. Especially, it can be instrumental to incorporate human knowledge and insight into decision making processes. Before a given scenario is generated, several other steps are needed. At first, we need to plan the scenarios, such as worst case, best case or current case, etc., in terms of the ideas in our mind. Then we input the required data or parameters into relevant models to generate scenarios. Finally, we test different scenarios, and from which some knowledge is extracted. Again, some prediction models about shoreline change and sea level rise will be involved in the procedure. The visualization toolkit in the next subsection will support the entire procedure.

Visualization toolkit will provide some basic visual forms. Specially, there are some aspects of functions that are worthwhile to emphasize in the toolkit. Firstly, we endeavor to organically integrate specialized data and information on coastal erosion into GIS. In fact, visualization technique and specialized computational model have been developing in separation. And recent research indicates that GIS has been one of the most recognizable tools for managers (Tribbia and Moser, 2008). Hence, the integrated representation is feasible and necessary. It will provide insight into the hidden pattern and trend for end users. The second is to visualize the evolution process and trend of coastal elements by predictive simulation models. The data about coastal elements, such as shoreline, tidal vegetation, reclamation, nearshore sediment movement, etc., were captured at discrete time intervals without intermediate details. The function allows us to understand their complete evolution process to some extent. And the third is to link coastal landscape and dynamic elements with Digital Elevation Model (DEM) by extensive texture and 3D model. Some improved interpolation algorithms, like fractal Brownian motion (fBm), wavelet, etc., are used to enhance the accuracy and visual effects of DEM. In addition, it is important to display the uncertainty of data and results, for instance, historical shorelines and predicted shorelines.

\section{RISK ASSESSMENT OF COASTAL EROSION IN THE YANGTZE DELTA}

In this section, we will give the details of risk assessment for our study area that based on the DSF, especially GIS-based risk assessment model aforementioned. The study area comprises the whole coasts of Shanghai and the partial coasts of Taicang, Haimen and Qidong in Jiangsu province.

Risk assessment has varied definitions and is widely used in various fields (Del Río and Gracia, 2009; Eurosion, 2004; UN/ISDR, 2004). Usually, a whole risk assessment encompasses vulnerability assessment and hazard assessment (UN/ISDR, 2004). The former, which is often linked to the physical dimensions to determine the area, probability and/or intensity of occurrence of a hazard under specified conditions; the latter determines the damage potential of a hazard, it is often related to the socio-economic and human dimensions. Respectively, they depend on a set of vulnerability indicators and impact indicators. The resulting risk index (RI), as a single risk measurement, can be derived by combining the two aspects.

According to the steps described above, some primary indicators, which can represent the essential physical and socio-economic characteristics of the specified coastal system, need to be first selected to segment the shorelines into the relatively homogeneous units. These primary indicators include administrative boundary, population density, geological types, and coastal characteristics. The full segmentation procedure requires an intersection operation of four different segmentation results related to these four indicators, and finally products 40 segments for the whole shorelines of the study area.

The selections of vulnerability and impact indicators were followed by some premises, including representativeness, independence, availability and easy to use. Meanwhile, according the specialists' suggestions and some published literatures (Feng and Xia, 2003; Li and Yang, 2001; Wang et al., 1999), the 10 vulnerability indicators were identified as:

$$
\begin{aligned}
& \text { - coastal elevation } \\
& \text { - coastal slope } \\
& \text { - average annual deposit volume } \\
& \text { - shoreline change rates } \\
& \text { - tidal range } \\
& \text { - significant wave height } \\
& \text { - relative sea level rise } \\
& \text { - intertidal width } \\
& \text { - intertidal vegetation type } \\
& \text { - intertidal vegetation zone width; }
\end{aligned}
$$

and the 3 impact indicators were identified as:

$$
\begin{aligned}
& \text { - population density } \\
& \text { - land use type } \\
& \text { - ecological hotspots. }
\end{aligned}
$$


Then both vulnerability and impact indicators were quantified or classified as numerable variables. Based on field surveys, the most recent seawall was interpreted from the Landsat TM images of April 25, 2008, and a polyline feature class, as assessment baseline, was produced in ArcGIS. Most of variables were calculated in a buffer zone of certain width, and these values were corresponding to each homogeneous unit. The variable of "coastal elevation" represents the percentage of the total area with elevation less than $2.4 \mathrm{~m}$ above the mean sea level in a $5 \mathrm{~km}$ wide buffer zone landwards from the assessment baseline. The "coastal slope" was calculated in a $2 \mathrm{~km}$ wide buffer zone that $1 \mathrm{~km}$ landwards and seawards, respectively, from the assessment baseline. The widths of buffer zones for "average annual deposit volume", "significant wave height" and "relative sea level rise" are, respectively, $2 \mathrm{~km}, 5 \mathrm{~km}$ and $5 \mathrm{~km}$ seawards from the assessment baseline. "Intertidal width" refers to average intertidal width from assessment baseline to $2 \mathrm{~m}$ isobaths. And the main land use type, as the variable "land use type", was identified from Landsat TM images in $2 \mathrm{~km}$ buffer zone landwards from the assessment baseline. Vegetation data, which were interpreted from TM images based on field surveys, represents the vegetation outside the seawalls.

Subaqueous topographic data and elevation data were obtained from digitized nautical charts and 1:50,000 scale topographic map, respectively. Landsat TM images of 1990 to 2008 were used to extract shorelines. Global mean sea level data with $1 / 3$ of a degree resolution provided by AVISO is available at http://www . aviso.oceanobs.com/en/news/ocean-indicators/meansea-level/. Significant wave height was simulated by SWAN wave model based on 11-year (1995-2005) monthly climatological data set from NOAA/NESDIS/National Climatic Data Center website (http://www.ncdc.noaa.gov/oa/rsad/seawinds . html). Population density data were obtained from the Gridded Population of the World version 3 (GPWv3) data set with 2.5 arcminutes resolution (CIESIN/FAO/CIAT, 2005).

Then, depending on the nature of each of these variables, they were assigned ranks ranging from 1 to 5 , with 1 representing minimum vulnerability/hazard and 5 representing maximum vulnerability/hazard.

Before evaluating the vulnerability and hazard, these variables must be weighted based on their relative importance in determining the coastal erosion vulnerability and hazard. The aims have two aspects: to avoid the underestimation or overestimation of the contribution of any variable; and to incorporate the specialists' knowledge into the DSF. To assign the objective and reliable weights for the variables, an Analytic Hierarchy Process (AHP), has been extensively used in almost all the applications related to Multiple Criteria Decision Making (MCDM) in the last 20 years (Ho, 2008), was employed for the variables weightings. According to the fundamental scale of absolute numbers (Saaty, 2008), we derived the priority scales for each variable based on the judgments of experts, and to construct the pairwise comparison matrix. For the 10 vulnerability indicators, the derived weights were, respectively, 0.182, 0.182, 0.264, 0.104, $0.023,0.023,0.016,0.119,0.035$ and 0.051 with a consistency ratio of 0.037 ; and for the 3 impact indicators, they were, respectively, $0.751,0.178$ and 0.070 with a consistency ratio of 0.025 . The Vulnerability Index (VI) was built by calculating the weighted sum of the 10 variables (Eq. 1):

$$
\mathrm{VI}_{j}=\sum_{i=1}^{n} w_{i} f_{i j}, i=1,2, \cdots, n ; j=1,2, \cdots, m
$$

where, $\mathrm{VI}_{j}$ is the VI for the $j$ th homogeneous unit; $w_{i}$ is the weight for the $i$ th vulnerability indicator; $f_{i j}$ is the scale for the $i$ th vulnerability indicator in the $j$ th homogeneous unit; $m$ and $n$ are the number of the homogeneous units and the vulnerability indicators, respectively. The calculation of Hazard Index (HI) was analogous to Eq. 1. And furthermore, the Risk Index (RI) was obtained by a simple weighted average of VI and HI. The weights for VI and $\mathrm{HI}$ are, respectively, 0.75 and 0.25 . Finally, the RI was normalized as a percentage of 0 to 100 (Figure 2).

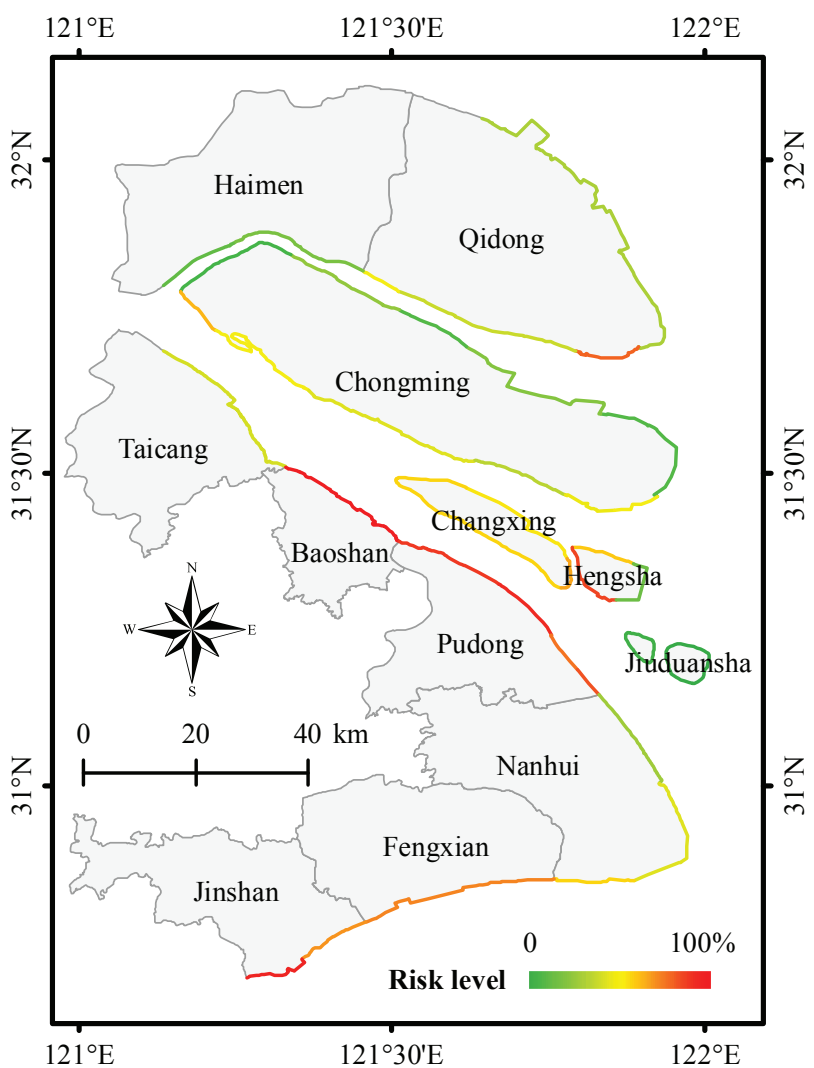

Figure 2: Distribution of risk level for the study area

The results show that the mean of RIs is $45.5 \%$. The values over $50 \%$ of RI appear in 17 shoreline segments, amounts to over $35 \%$ of the total length of all shorelines in study area. The shoreline segments with RIs being over $60 \%$ are mainly distributed in the four districts of Baoshan, Pudong, Fengxian and Jinshan. Moderate values of RI appear in the southern part of Qidong and Chongming Island, most parts of Changxing Island, and the southern part of Nanhui district. And the low values appear in Chongming Dongtan, Jiuduansha, and the North Branch.

\section{DISCUSSION AND CONCLUSIONS}

As Tribbia and Moser (2008) reminded us, there exists a disconnection between science and practice in coastal management. Currently, it is scientists and researchers in the institute who are engaged in the study of coastal erosion, while the managers who need to prepare the impact of coastal erosion. In order to assure a scientific decision making, managers should adequately understand the information about coastal erosion. There is urgent need for a bridge between scientists and managers. The proposed DSF partially meets the requirement. And it has some distinctive characteristics. First of all, with GIS and the linear referencing database system, the framework will be scalable that allows the incorporation of a broad range of data and models when they are available. This is especial suitable to the developing coastal area. 
Meanwhile, the scenario generator and visualization toolkit make it possible that the communication and synergetic work between humans and computers. But to implement the framework some challenges still exist.

For the Yangtze Delta, data remains one of the biggest challenges. Although a great deal of research has been focused on estuarine and coastal environment for the past decades, the data have been sporadically holding by individuals and communities. A wellorganized data collection and sharing mechanism is strongly suggested. And the technique of capturing data is also problematic in highly dynamic environments (Wright, 2009). Researchers must rely on the appropriate sampling strategy to guarantee that the inherent characteristic of dynamic elements can be faithfully preserved. Alternatively, some parameters can be retrieved from remote sensing observations.

Additionally, some models are unavoidably involved in the DSF presented in this paper. Especially, the results from deterministric models should be carefully considered because, as claimed by Purvis et al. (2008), this kind of models mask the uncertainty of the complex systems and the expert knowledge is excluded from them. Dawson et al. (2009) also contested that probabilistic methods should be adopted to predict coastal erosion. Indeed for a given model, the validity of the result depends on many factors (Szlafsztein and Sterr, 2007). It is the reason why the scenario generator and the visualization toolkit are involved in the DSF in this paper. The evolution and involvement of human knowledge are indispensable in the decision making processes of complex systems.

Under the influence of global warming, there may be more urgent need to carry out the risk assessment of coastal erosion for the Yangtze Delta than other coastal areas in China. This paper presented a decision support framework (DSF) for the risk assessment of coastal erosion in Yangtze Delta. It is worthwhile to mention that we developed a GIS-based risk assessment model for the muddy coasts of Yangtze Delta. And the AHP method, which is instrumental in combining computer intelligence and experts' knowledge, was used to weight variables. The assessment results show the validity of the approach. But as described above, there are still some challenges for the case of Yangtze Delta due to the well-known reasons for developing areas. So there is still some way to go before the proposed DSF can be put into practice. We hope that our proposal can help local authorities understand the potential of coastal erosion risk and take precautions in advance. Finally, the proposed DSF, especially including the vulnerability indicators and the impact indicators, is defined for the Yangtze Delta in this paper. But, in view of its flexibility, it also available for a wide range of muddy coastal area.

\section{ACKNOWLEDGEMENTS}

We gratefully acknowledge the support of the Programme Strategic Scientific Alliances between China and the Netherlands (2008D FB90240), the State Oceanic Administration of China (200705020), the state key laboratory special fund from the Ministry of Science and Technology of China, the Doctoral Fund of Shanghai Ocean University. We also sincerely thank Dr. Ge Jianzhong for his help in simulating the significant wave height. A special thank is due to the anonymous reviewers for their valuable comments and suggestions for the improvement of the manuscript.

\section{References}

Alter, S., 2004. A work system view of DSS in its fourth decade. Decision Support Systems 38(3), pp. 319-327.

Bird, E. C. F., 1985. Coastline changes. Wiley \& Sons, New York.
Cai, F., Su, X., Liu, J., Li, B. and Lei, G., 2009. Coastal erosion in China under the condition of global climate change and measures for its prevention. Progress in Natural Science 19(4), pp. 415-426.

Chen, J. Y., Shen, H. T. and Yun, C. X., 1988. Process of dynamics and geomorphology of the Changjiang Estuary (in Chinese). Shanghai Science and Technology Press, Shanghai.

Chen, J. Y., Yu, Z. Y. and Yun, C. X., 1959. Development of the geomorphology of the Changjiang delta. Acta Ecologica Sinica (in Chinese) 25(3), pp. 201-220.

Chen, X. Q., Zong, Y. Q., Zhang, E. F., Xu, E. G. and Li, S. J., 2001. Human impacts on the Changjiang (Yangtze) River basin, China, with special reference to the impacts on the dry season water discharges into the sea. Geomorphology 41(2-3), pp. 111-123.

CIESIN/FAO/CIAT, 2005. Gridded Population of the World: Future Estimates (GPWFE)). Palisades, NY: Socioeconomic Data and Applications Center (SEDAC), Columbia University. Available at http://sedac.ciesin. columbia.edu/gpw.

Dawson, R., Dickson, M., Nicholls, R., Hall, J., Walkden, M., Stansby, P., Mokrech, M., Richards, J., Zhou, J., Milligan, J., Jordan, A., Pearson, S., Rees, J., Bates, P., Koukoulas, S. and Watkinson, A., 2009. Integrated analysis of risks of coastal flooding and cliff erosion under scenarios of long term change. Climatic Change 95(1), pp. 249-288.

Del Río, L. and Gracia, F. J., 2009. Erosion risk assessment of active coastal cliffs in temperate environments. Geomorphology 112(1-2), pp. 82-95.

Eurosion, 2004. Living with coastal erosion in europe: Sediment and space for sustainability. guidance document for quick hazard assessment of coastal erosion and associated flooding. Technical report, Service contract B43301/2001/329175/MAR/B3 "Coastal erosion - Evaluation of the need for action" Directorate General Environment, European Commission.

Feng, A. P. and Xia, D. X., 2003. Grading of coastal erosion disaster situation. Coastal Engineering (in Chinese) 22(2), pp. 6066.

Gao, S. and Wang, Y. P., 2008. Changes in material fluxes from the Changjiang river and their implications on the adjoining continental shelf ecosystem. Continental Shelf Research 28(12), pp. 1490-1500.

Gong, S. L., 2008. The study on acting factors and systemic control of land subsidence in Shanghai (in Chinese). Doctoral, East China Normal University.

Han, Z. S., Jayakumar, R., Liu, K., Wang, H. and Chai, R., 2008. Review on transboundary aquifers in People's Republic of China with case study of Heilongjiang-Amur River Basin. Environmental Geology 54(7), pp. 1411-1422.

Ho, W., 2008. Integrated analytic hierarchy process and its applications - a literature review. European Journal of Operational Research 186(1), pp. 211-228.

Hori, K., Saito, Y., Zhao, Q. H. and Wang, P. X., 2002. Architecture and evolution of the tide-dominated Changjiang (Yangtze) River delta, China. Sedimentary Geology 146(3-4), pp. 249264. 
Jones, P. D., Tyler, A. O. and Wither, A. W., 2002. Decisionsupport systems: Do they have a future in estuarine management? Estuarine Coastal and Shelf Science 55(6), pp. 993 1008 .

Lau, M., 2005. Integrated coastal zone management in the People's Republic of China-An assessment of structural impacts on decision-making processes. Ocean \& Coastal Management 48(2), pp. 115-159.

Li, H. P. and Yang, G. S., 2001. Determination of classification and risk in the coastal zone of Yangtze Delta and North Jiangsu. Journal of Natural Disasters (in Chinese) 10(4), pp. 20-25.

Milliman, J. D., Huang-ting, S., Zuo-sheng, Y. and H. Mead, R., 1985. Transport and deposition of river sediment in the Changjiang estuary and adjacent continental shelf. Continental Shelf Research 4(1-2), pp. 37-45.

Nicholls, R., Wong, P., Burkett, V., Codignotto, J., Hay, J., McLean, R., Ragoonaden, S. and Woodroffe, C., 2007. Coastal systems and low-lying areas. In: Climate change 2007: impacts, adaptation and vulnerability, Cambridge University Press, Cambridge, UK, pp. 315-356.

Power, D. J., 2008. Decision support systems: A historical overview. In: F. Burstein and C. W. Holsapple (eds), Handbook on Decision Support Systems 1, Springer, pp. 121-140.

Purvis, M. J., Bates, P. D. and Hayes, C. M., 2008. A probabilistic methodology to estimate future coastal flood risk due to sea level rise. Coastal Engineering 55(12), pp. 1062-1073.

Saaty, T. L., 2008. Decision making with the analytic hierarchy process. International Journal of Services Sciences 1(1), pp. 83-98.

Saito, Y., Yang, Z. S. and Hori, K., 2001. The Huanghe (Yellow River) and Changjiang (Yangtze River) deltas: a review on their characteristics, evolution and sediment discharge during the Holocene. Geomorphology 41(2-3), pp. 219-231.

Shen, H., Guo, C., Zhu, H., Xu, H., Yun, C. and Chen, B., 1988. A discussion on the change and origin of turbidity maximum in the Changiiang Estuary. In: J. Chen, H. Shen and C. Yu (eds), Process of Dynamics and Geomorphology of the Changjiang Estuary (in Chinese), Shanghai Scientific and Technical Publishers, Shanghai, pp. 216-228.

Sheng, J. F. and Zhu, D. K., 2002. Discussion about coastline erosion and management. Marine Science Bulletin (in Chinese) 21(4), pp. 50-57.

Shi, C., Hutchinson, S. M., Yu, L. and Xu, S., 2001. Towards a sustainable coast: an integrated coastal zone management framework for shanghai, People's Republic of China. Ocean \& Coastal Management 44(5-6), pp. 411-427.

Shi, Y. F., Zhu, J. W., Xie, Z. R., Ji, Z. X., Jiang, Z. X. and Yang, G. S., 2000. Prediction and prevention of the impacts of sea level rise on the Yangtze River Delta and its adjacent areas. Science in China Series D-Earth Sciences 43(4), pp. 412-422.

Szlafsztein, C. and Sterr, H., 2007. A gis-based vulnerability assessment of coastal natural hazards, state of para, brazil. Journal of Coastal Conservation 11(1), pp. 53-66.

Tribbia, J. and Moser, S. C., 2008. More than information: what coastal managers need to plan for climate change. Environmental Science \& Policy 11(4), pp. 315-328.
UN/ISDR, 2004. Living with risk: A global review of disaster reduction initiatives. Technical report, United Nations InterAgency Secretariat of the International Strategy for Disaster Reduction, Geneva, Switzerland.

Uran, O. and Janssen, R., 2003. Why are spatial decision support systems not used? some experiences from the netherlands. Computers, Environment and Urban Systems 27(5), pp. 51126.

Van Kouwen, F., Dieperink, C., Schot, P. and Wassen, M., 2008. Applicability of decision support systems for integrated coastal zone management. Coastal Management 36(1), pp. 19-34.

Wang, W. H., Wu, S. Y. and Chen, X. Y., 1999. Research on the assessment method of the coastal erosion disaster. Journal of Natural Disasters (in Chinese) 8(1), pp. 71-77.

Westmacott, S., 2001. Developing decision support systems for integrated coastal management in the tropics: Is the ICM decision-making environment too complex for the development of a useable and useful DSS? Journal of Environmental Management 62(1), pp. 55-74.

Wiggins, S., 2004. Coastal decision support systems in the UK. CoastNet Bulletin 8(3), pp. 18.

Wright, D. J., 2009. Spatial data infrastructures for coastal environments. In: X. Yang (ed.), Remote Sensing and Geospatial Technologies for Coastal Ecosystem Assessment and Management, Springer, pp. 91-112.

Xia, D. X., Wang, W. H., Wu, G. Q., Cui, J. R. and Li, F. L., 1993. Coastal erosion in China. Acta Geographica Sinica (in Chinese) 48(5), pp. 468-476.

Yang, S. L., Ding, P. X. and Chen, S. L., 2001. Changes in progradation rate of the tidal flats at the mouth of the Changjiang (Yangtze) River, China. Geomorphology 38(1-2), pp. 167180.

Yang, S. L., Zhang, J. and Xu, X. J., 2007. Influence of the Three Gorges Dam on downstream delivery of sediment and its environmental implications, Yangtze River. Geophysical Research Letters 34(10), pp. L10401.

Yang, Z., Wang, H., Saito, Y., Milliman, J. D., Xu, K., Qiao, S. and Shi, G., 2006. Dam impacts on the Changjiang (Yangtze) River sediment discharge to the sea: The past 55 years and after the Three Gorges Dam. Water Resources Research 42(4), pp. W04407.

Zhang, K. Q., Douglas, B. C. and Leatherman, S. P., 2004. Global warming and coastal erosion. Climatic Change 64(1), pp. 4158.

Zhang, Y., Swift, D. J. P., Yu, Z. Y. and Jin, L., 1998. Modeling of coastal profile evolution on the abandoned delta of the huanghe river. Marine Geology 145(1-2), pp. 133-148.

Zhou, D., Liang, Y. B. and Zeng, C. k., 1994. Oceanology of China seas. Vol. Volume II, Kluwer Academic Publishers, Dordrecht; Boston.

Zuo, X., Aiping, F., Ping, Y. and Dongxing, X., 2009. Coastal erosion induced by human activities: A northwest bohai sea case study. Journal of Coastal Research 25(3), pp. 723-733. 